\title{
Masculinidade hegemônica, vulnerabilidade e prevenção ao HIV/AIDS
}

\author{
Hegemonic masculinity, vulnerability \\ and the prevention of HIV/AIDS
}

Joilson Santana Marques Junior ${ }^{1}$

Romeu Gomes ${ }^{2}$

Elaine Ferreira do Nascimento ${ }^{2}$

${ }^{1}$ Departamento de Formação Básica do Serviço Social, Centro de Ciências Sociais, Universidade do Estado do Rio de Janeiro. Rua São Francisco Xavier 524/8019/bl.E, Maracanã. 20550-013 Rio de Janeiro RJ. joutromundo2000@ yahoo.com.br

${ }^{2}$ Departamento de Ensino, Instituto Fernandes

Figueira, Fundação Oswaldo Cruz

\begin{abstract}
The study aims to examine the relationship between masculinity, vulnerability and the prevention of HIV/AIDS, based on reports from young men from the so-called urban working classes, taking into account not only the meanings attributed to prevention by these subjects, but also considering the dialectical relationship between the individual and society. The conceptual framework encompasses the three main aspects of hegemonic masculinity, prevention and vulnerability. This involves qualitative research based on the perspective of dialectical hermeneutics that uses the method of interpretation of meanings. The analysis yielded two main results, namely hegemonic masculinity as a vulnerability factor, and myths and prejudices as factors of vulnerability to HIV/AIDS. By way of conclusion, it reinforces the need for discussion of prevention encompassing the need to put on the agenda the construction of the sex/gender system around which to articulate the social meanings of masculinity and femininity that influence the structural plan of affective sexual relations in general and HIV/AIDS in particular.
\end{abstract}

Key words Masculinity, Vulnerability, Prevention of HIV/AIDS
Resumo O estudo tem como objetivo analisar as relações entre masculinidade, vulnerabilidade e prevenção do HIV/AIDS, com a ancoragem em narrativas de homens jovens pertencentes às chamadas classes trabalhadoras urbanas, levando em conta não só os sentidos atribuídos à prevenção por parte desses sujeitos, mas também considerando a relação dialética entre individuo e sociedade. O referencial conceitual engloba três eixos masculinidade hegemônica, prevenção e vulnerabilidade. Trata-se de uma pesquisa qualitativa baseada na perspectiva da hermenêutica dialética que utiliza o método de interpretação de sentidos. A análise produziu dois eixos como resultados: A masculinidade hegemônica como fator de vulnerabilidade; Mitos e preconceitos como fatores de vulnerabilidade ao HIV/AIDS; Em termos de conclusão, reforça-se a necessidade da discussão acerca da prevenção encampar a necessidade de colocar na ordem do dia a construção do sistema sexo/gênero em volta do qual se articulam os significados sociais da masculinidade e da feminilidade que influenciam estruturalmente o plano das relações afetivo sexuais, em geral, e a prevenção do HIV/AIDS, em específico.

Palavras-chave Masculinidade, Vulnerabilidade, Prevenção do HIV/AIDS 


\section{Introdução}

A discussão acerca da saúde do homem vem sendo ampliada nas ultimas décadas ${ }^{1-8}$. Entretanto, os próprios autores dessa discussão concluem que são necessárias novas produções nessa área, de modo a dialogar com outras particularidades, quais sejam: raça/etnia, classe, faixa etária, bem como novos olhares sobre as masculinidades e sua relação com o processo saúde/doença.

No cenário dessa discussão, destacam-se questões relacionadas tanto à prevenção quanto à disseminação do HIV/Aids e, no interior destas, os homens jovens são apontados como mais vulneráveis do que os adultos ${ }^{6-8}$. Rios ${ }^{9}$, por exemplo, observa que vem se intensificando o aumento da incidência de HIV/Aids nos grupos representados pelos adolescentes e jovens.

Antunes et al. ${ }^{10}$ colocam a necessidade de se analisar as dificuldades específicas dos jovens em se tornarem agentes de sua vida sexual, o que os tornaria menos passíveis de infecção dessa epidemia. Esses dois estudos podem servir de base para a necessidade de ainda se empreender pesquisas relacionadas à prevenção do HIV/Aids, tendo como foco homens jovens a partir de uma perspectiva sociocultural.

Em relação aos homens jovens brasileiros, na literatura, estes vêm sendo focalizados em meio a situações de vulnerabilidade, ancorada na hipótese explicativa de que a sua socialização tem estimulado a associação de virilidade à 'impetuosidade', ao desejo sexual masculino 'incontrolável', à ideia de que é natural do homem 'correr riscos' $e$ que o controle das consequências desejadas ou indesejadas do sexo é tarefa feminina ${ }^{11}$.

A partir dessa perspectiva, objetivamos analisar as relações entre masculinidade, vulnerabilidade e prevenção do HIV/AIDS, com a ancoragem em narrativas de homens jovens pertencentes às chamadas classes trabalhadoras urbanas, levando em conta não só os sentidos atribuídos à prevenção por parte desses sujeitos, mas também considerando a dialética desses sentidos com significados estruturais e estruturantes, modelados por aspectos socioculturais.

Partimos da premissa de que as construções socioculturais da masculinidade hegemônica contribuem na forma como os sujeitos atribuem sentidos à prevenção, pois, este referencial torna-o mais vulnerável na medida em que diminui sua percepção acerca da suscetibilidade à infecção pelo HIV/AIDS.

\section{Marco teórico}

A nossa perspectiva analítica se pauta em três marcos teórico-conceituais: masculinidade, prevenção e vulnerabilidade.

No que se refere à masculinidade, com base em Gomes ${ }^{3}$, relacionamo-la a modelos culturais de gênero que estruturam pensamentos, afetos e condutas voltados para a identidade de ser homem. Quanto mais os homens se aproximam desses modelos aceitos culturalmente, maior será a possibilidade de terem a sua masculinidade atestada.

Ainda que concebamos a masculinidade no plural, não podemos desconsiderar que entre os diversos modelos pode haver um que, embora não seja totalmente dominante, hegemonicamente assume uma posição de autoridade cultural e de liderança, em relação à ordem de gênero como um todo ${ }^{12}$. Esse modelo se estrutura basicamente a partir de dois eixos: heterossexualidade e dominação ${ }^{13}$.

Observamos ainda que a masculinidade hegemônica, além de espelhar a figura do homem branco heterossexual de classe média alta, pode estimular aspectos como:

a força, o poder sobre os mais fracos (sejam as mulheres ou outros homens), a coragem, a atividade (aqui entendida como o contrário de passividade, inclusive sexual), a potência, a resistência, a invulnerabilidade, entre outras qualidades consideradas positivas ${ }^{3}$.

O modelo hegemônico de masculinidade tem sido questionado ao se abordar a prevenção e a disseminação do HIV/AIDS. A discussão de Greig $^{14}$ é um exemplo desse questionamento, quando coloca em foco esse modelo como um possível empecilho ao cuidado com a saúde, expondo os homens a maiores riscos de contração dessa doença.

Ao mesmo tempo esse padrão requer a contínua exposição a situações de maior risco, devido à socialização dos homens para a coragem, e a ideia de que é "próprio dos homens" não recusar nenhuma possível relação sexual bem como a redução do exercício sexual à penetração, o que dificulta a própria discussão de saúde entre os homens ${ }^{4}$. Ao nos determos mais acuradamente sobre os aspectos citados percebemos que eles afastam os homens de se perceberem como pessoas passíveis de contrair ou transmitir HIV/AIDS.

A prevenção enquanto conceito está permeado por significados que vão desde a ideia da prevenção da doença, que foi seu marco inaugural, até a perspectiva dos direitos humanos nos dias atuais, dentro dessa polissemia de sentidos pro- 
curamos abordar de forma sintética os debates que contribuem com a concepção adotada para a pesquisa.

A prevenção toma um corpus teórico a partir da medicina preventiva que rediscute o modelo assistencial curativo. Nessa abordagem, a expressão vinculava-se à noção de impedir o aparecimento e o desenvolvimento da doença, através de ações que privilegiassem a orientação comportamental, que atendessem a uma coletividade como melhora nos ambientes de trabalho e com imunizações, entre outras ${ }^{15}$.

Bastos e Szwarcwald ${ }^{16}$ expressam que as ações preventivas para além do enfoque individual devem vislumbrar uma atuação que contribua na transformação das relações sociais e no combate às iniquidades sociais, pois, para o autor, a relevância encontra-se na soma de determinantes sociais que impactam diretamente nas escolhas e nos projetos individuais, nessa perspectiva a prevenção não pode ser compreendida separando sujeito de coletivo, indivíduo e sociedade.

Por sua vez, Paiva et al. ${ }^{17}$ situam a prevenção no plano dos direitos humanos e redefine a mesma a partir de uma concepção que ultrapasse a prescrição de normas e comportamentos de modo a construir uma relação dialógica com os sujeitos.

A partir desse breve debate, pretendemos situar a prevenção, neste estudo, como uma prática social composta por um dimensionamento que extrapola a noção de prevenção enquanto conjunto de ações e medidas específicas direcionadas para uma doença ou agravo, e sim como ação que se inscreve no viver cotidiano dos sujeitos, nos contextos em que os mesmos estão imersos. Assim, partilhamos da ideia de que a prevenção resulta de uma grande construção coletiva que envolve sujeitos diversos, portadores de diferentes projetos de mundo, em contínua e imprescindivel interação material e simbólica ${ }^{18}$.

Desse modo, avançamos para o entendimento da prevenção como uma produção ao mesmo tempo individual e coletiva, em uma perspectiva de direito que vem ao encontro da ótica de estudar os sujeitos nas suas intersubjetividades dentro de seus panoramas de vida.

Em termos de conceito de vulnerabilidade, destacamos aspectos que tanto se relacionam à suscetibilidade a doenças e agravos, quanto àqueles que se relacionam à disponibilidade ou à carência e que se destinam à proteção das pessoas. Neste conceito, também se relacionam aspectos individuais, coletivos e contextuais ${ }^{19}$.

No que se refere à vulnerabilidade, em termos de prevenção ao HIV, esse conceito emerge com Mann et al. ${ }^{20}$ que o situa no âmbito das suscetibilidades de indivíduos e coletividades à infecção, adoecimento e morte por esse vírus. Ayres et al. ${ }^{2}$, ao sistematizarem esse conceitos, destacam que a vulnerabilidade em relação ao HIV/AIDS vincula-se a um conjunto de aspectos: individuais (basicamente relacionados a comportamentos que podem facilitar o adoecimento e/ou a infecção); sociais (relacionados a acesso de informação e aspectos sociopolíticos, dentre outros) e programáticos (compromisso das autoridades, ações intersetoriais e financiamento adequado, dentre outros).

$\mathrm{Na}$ medida em que a epidemia de HIV/AIDS vem sendo abordada a partir de uma multiplicidade de fatores, cuja influência na infecção pelo vírus supera o modelo calcado na noção epidemiológica do risco, o conceito de vulnerabilidade vem sendo amplamente focalizado. Em meio a essa multiplicidade de fatores, há estudos ${ }^{16,21}$ que apontam para o próprio modelo neoliberal como fator que intensifica a vulnerabilidade ao HIV/ AIDS, pois amplia as desigualdades sociais, diminui as políticas sociais, a disponibilidade de serviços públicos de saúde e consequentemente vulnerabiliza as chamadas classes trabalhadoras urbanas.

De um modo geral podemos dizer que todos são vulneráveis, pois apresentam questões que o fragilizam, porém, é importante perceber que a forma como se organiza a sociedade aumenta ou diminui a suscetibilidade dos sujeitos ao HIV/ AIDS.

\section{Metodologia}

O nosso corpo analítico é constituído por parte do acervo de narrativas produzidas pela pesquisa, de cunho qualitativo, "Sexualidade masculina e cuidados de saúde" 22 , que se propôs a analisar os sentidos atribuídos por homens à sexualidade masculina e aos cuidados de saúde no campo da sexualidade, desenvolvida com apoio do CNPQ e aprovadas pelo Comitê de Ética em Pesquisa do Instituto Fernandes Figueira/Fiocruz.

$\mathrm{O}$ acervo da pesquisa compreende 42 narrativas de homens jovens (20 pertencentes às chamadas classes trabalhadoras urbanas e 22 universitários) nascidos na segunda metade da década de 80 do século passado (com menos de 25 anos), que declararam ter iniciação sexual nos anos 90 e que, à época das entrevistas residiam, estudavam ou trabalhavam no Rio de Janeiro. No presente trabalho focalizaremos apenas os 
20 jovens de famílias das classes trabalhadoras urbanas.

Para a análise do acervo das narrativas, nos baseamos em princípios da hermenêutica-dialética, buscando caminhar na compreensão e na contextualização dos sentidos subjacentes às narrativas dos sujeitos investigados ${ }^{23}$.

O método de análise privilegiado neste trabalho foi a interpretação de sentidos que, segundo Gomes ${ }^{24}$, se baseia nos seguintes passos: (a) leitura exaustiva do material, formando um quadro com os aspectos comuns e dissonantes, gerais e singulares das narrativas, de modo a compreendê-las de forma conjuntural; (b) classificação de eixos temáticos das narrativas, buscando a articulação entre os textos e os subtextos presentes nas falas, e (c) discussão dos eixos temáticos tendo como referência os marcos teóricoconceituais (masculinidade, vulnerabilidade, prevenção do HIV/AIDS).

\section{Caracterização dos Sujeitos}

Os 20 homens jovens aqui focalizados residem na comunidade da Rocinha, da cidade do Rio de Janeiro. A pesquisa inicialmente não tinha como campo exclusivo essa comunidade, no entanto, ao seguir a lógica da técnica dos universos familiares ${ }^{25}$, o primeiro entrevistado era dessa comunidade, gerando assim sucessivos informantes da Rocinha.

A comunidade em questão, segundo os dados do censo 2000, apresenta um número de 50 mil habitantes, embora outras estimativas indiquem que o bairro possui cerca de 120 mil residentes majoritariamente descentes de nordestinos ${ }^{26}$.

$\mathrm{O}$ bairro está entre aqueles com mais baixo IDH 0,629 e encontra-se em situação díspar em relação aos seus vizinhos da Área Programática dois, que compreende os bairros da Zona sul da cidade, onde se encontra a maior concentração de renda e o melhor acesso aos serviços públicos. Ainda assim a Rocinha guarda suas próprias contradições, pois internamente existe uma hierarquização em termos de renda e de acesso aos parcos serviços existentes ${ }^{27}$.

De forma resumida esse é o território de vivência dos informantes. A partir da sua sociabilidade é que eles narram suas experiências, ideias e contradições, e estas se relacionam aos sentidos que atribuem à prevenção.

Dos 20 homens jovens, com base na classificação do Instituto Brasileiro de Geografia e Estatística (IBGE), 3 se declaram pretos, 9 pardos e 8 brancos. Em termos de renda familiar, 6 relataram que recebem mais de 1 a 2 salários mínimos, 5 mais de 2 a 3 salários mínimos, 3 mais de 3 a 5 salários mínimos e 6 pessoas não informaram a renda familiar. Ou seja, temos um grupo em que 14 participantes têm uma renda familiar de até 5 salários mínimos, sendo que existe uma alta concentração em torno da variável de 1 a 2 salários mínimos.

No que se refere às informações sobre o tema sexualidade, observamos que a média de iniciação sexual é 14,6 anos. Entre eles, 10 responderam que a primeira relação sexual havia ocorrido em casa, 9 relatam ter ocorrido fora de casa e 1 não informou e 1 não respondeu. Quanto ao uso de preservativo na última relação, 12 jovens responderam que fizeram uso do preservativo, 7 não fizeram e 1 não respondeu.

Essa aproximação com as informações geradas pela pesquisa original torna-se relevante à medida que um dos pressupostos da análise-interpretativa das narrativas compreende o conhecimento do contexto em que elas ocorrem.

\section{Resultados e Discussão}

\section{A masculinidade hegemônica como fator de vulnerabilidade}

Os homens jovens, em determinados momentos, para terem sua masculinidade reconhecida, conscientes ou não, podem reproduzir certos aspectos das marcas identitárias da masculinidade hegemônica. Indo nessa perspectiva, é importante ressaltar que apesar de os sujeitos da pesquisa residirem na referida comunidade, os jovens circulam pelos mesmos espaços de lazer e trabalho, partilham de alguns referencias territoriais e socioculturais, não se mantendo, portanto, isolados do contexto que estrutura as relações em nossa sociedade. Neste sentido, na construção de suas falas, há reflexos de modelos que circulam no imaginário social mais geral, que ultrapassam segmentos socioeconômicos.

No que se refere a padrões masculinos hegemônicos de sexualidade, na fala dos entrevistados, observou-se um reflexo da ideia de que o homem tem uma sexualidade desenfreada e sempre responde sexualmente frente a determinadas situações ${ }^{3}$.

A fala dos nossos sujeitos ilustra bem tal referencial:

Ele [o homem] vai sair pra rua e vai conhecer uma outra mulher ele não vai deixar de fazer [sexo] 
ele vai, vai querer fazer de camisinha porque ele não tem confiança na mulher, mas se não tiver também ele vai se sentir obrigado a fazer porque ele saiu da noite pra [fazer sexo] e pegar o máximo de mulher possivel, mesmo ele sendo casado [...] quando está na hora do vamos ver, que não tem camisinha, aí seu cérebro fica desse tamanho, aí você vai pelos seus instintos carnais (Randal).

Vou ainda cara, na boa ainda, até vou [fazer sexo] porque conheço ela [...] e se pintar uns dias da gente [...] rolar um transa eu vou. Se não quiser camisinha, eu vou cara (Rivo)

Fazendo coro, ainda, ao padrão hegemônico de sexualidade masculina, um dos nossos sujeitos resume:

O homem não pensa com a cabeça de cima, pensa com a de baixo (Rivelino).

Ancorados nessas falas, podemos considerar que a reprodução de aspectos do modelo de masculinidade hegemônica pode fazer com que os homens jovens se tornem mais vulneráveis à transmissão do HIV/AIDS, influenciando a não incorporação de informações que visem à produção de mudanças de comportamento e, por consequência, dificultando a adesão às campanhas voltadas para a prevenção dessa transmissão. Ainda que as informações por si só não garantam a adoção de práticas de sexo mais seguras entre os homens jovens, a forma como elas são apresentadas precisa levar em consideração os sujeitos que as recebem.

O fato de observarmos reflexos desse referencial nas falas dos nossos sujeitos não significa necessariamente que eles tenham uma adesão incondicional a esse. Ao contrário, em determinadas falas, há críticas sobre esse posicionamento, fazendo com que a ideia de que a sexualidade masculina é desenfreada e concorra com as informações acerca da prevenção do HIV/AIDS, como as relacionadas ao uso de preservativo. Nesse sentido, um dos jovens observa:

Se não tivesse camisinha comigo não rolava e eu já até ouvi [...] você é maior otário não sei o quê, não gosta de mulher [...] gostar de mulher eu gosto, mas eu não quero é ficar doente depois, pegar uma gonorreia, uma AIDS (Radamés)

Junto a isso, rompendo esse padrão de sexualidade masculina desenfreada, insurge a fala que aponta para o domínio sobre o exercício sexual como algo necessário para a construção do masculino, indicando a existência de outras possibilidades do ser homem:

Às vezes temos tentações [mas] se a gente não tiver um domínio e tal [...] fazemos coisas que não era para fazer no momento da zueira (Rodrigo)
Por último, observamos que, assim como na literatura sobre o assunto, falas dos nossos sujeitos podem servir de base para a hipótese de que o modelo de masculinidade hegemônica pode influenciar a adoção do preservativo nas relações entre os gêneros, principalmente quando as diferenças se transformam em desigualdades, na medida em que o uso de preservativo nas relações sexuais costuma estar subordinado à decisão masculina ${ }^{10}$. Essa hipótese se torna bastante crível, uma vez que, em geral, os nossos entrevistados não desenvolveram uma reflexão sobre o compartilhamento das decisões acerca do uso do preservativo entre os gêneros.

Ainda que observemos a influência da masculinidade hegemônica no que se refere à subordinação da decisão feminina à masculina, não podemos descartar reflexos de outras masculinidades em que as relações de gênero podem ser mais horizontais. Ilustrando esse achado, destacamos o depoimento que segue:

O que é muito importante que todos os jovens compreenda que tem que ter o respeito, isso que eu falei, respeito saber fazer o que a garota gosta, se a garota não quer fazer uma coisa você tem que respeitar e fazer apenas o que ela aceita e tal... (Romário)

Essas frestas na hegemonia da masculinidade que permitem a insurreição de outros modelos podem ser espaços de investimento na possibilidade de homens jovens também serem capazes de estabelecer negociações nas suas relações, aí podendo ser incluído o uso do preservativo.

\section{Preconceitos e mitos como fatores de vulnerabilidade ao HIV/AIDS}

A adoção de medidas preventivas ao HIV/ AIDS pode ser atravessada por preconceitos e mitos, de forma consciente ou não. Nesse sentido, essa adoção pode - de um lado - ressuscitar posicionamentos sexistas e homofóbicos, dentre outro, e - de outro lado - a reificação de ideias que, embora em outros contextos sejam procedentes, no caso do HIV/AIDS não asseguram uma prevenção eficaz. Especificamente em relação ao mito, neste estudo, essa expressão relaciona-se a valores, crenças e dogmas utilizados como sinônimo de verdade ${ }^{28}$.

Em se tratando de preconceitos, destaca-se que - comumente - pessoas que não são vistas dentro de certo padrão costumam ser percebidas como aquelas que contribuem para a disseminação da doença. Alguns desses preconceitos podem ter sido fundamentados a partir do quadro epidemiológico do início da epidemia. Nesse 
sentido, as primeiras constatações de maior frequência de casos de AIDS entre pessoas que não eram consideradas dentro dos padrões heterossexuais pode até os dias atuais reforçar preconceitos. Assim, esse quadro inicial mudou, mas os preconceitos continuam atualizando-o.

A fala de um dos nossos entrevistados pode trazer resquícios desse preconceito:

quando vai transar com o homem, quando o cara é bissexual aí pô, aí tem que ter uma prevenção maior porque é muito forte, pode [passar] uma doença pra outro assim, o sexo anal, por exemplo, ele é mais fácil também, tem várias bactérias, varias paradas no ânus que é mais fácil de pegar do que na vagina (Rodrigo).

O que se percebe é a recorrência na hierarquia de expressões de sexualidade onde se sagrou a heterossexualidade como forma de sexualidade "normal" e a monogamia como pré-requisito do "bom sexo" em contraposição ao sexo anal visto como "sujo" e marcador de contágio ${ }^{29}$.

Essa fala, que ao mesmo tempo se refere a preconceitos e mitos, aponta o sexo anal como perigoso e arriscado e o sexo vaginal como menos arriscado, e que de certa forma é incorporado como uma prática correta e moralmente legítima e que se pode abrir mão do uso do preservativo. Portanto, ainda se faz presente no imaginário social a percepção da AIDS como doença vinculada a desejos não hegemônicos, considerado como o "mau sexo" em contraposição ao “sexo bom" praticado por homens e mulheres, preferencialmente no espaço monogâmico com fins procriativos ${ }^{29}$.

Relacionado ou não a esse ideário, observa-se que as medidas preventivas voltadas para o HIV/ AIDS que partilham do dispositivo da heterossexualidade compulsória podem contribuir para que seja criada uma falsa sensação de proteção, a partir do suposto pertencimento a "norma".

No que tange a mitos, observa-se que certas informações que os sujeitos têm acerca da prevenção do HIV/AIDS nem sempre se sustentam como medidas eficazes contra a disseminação da doença. De certa forma, essas ideias que, em outros contextos, poderiam ser adequadas em termos de prevenção de doenças em geral, no caso em questão, podem ser consideradas como mitos. Em outras palavras, certos posicionamentos considerados válidos para certos propósitos são deslocados para outros contextos que podem invalidá-los.

Os mitos relacionados à transmissão do HIV estão ligados às construções socioculturais erigidas a partir de concepções de gênero e de sexualidade. Eles são estabelecidos não somente por questões relacionadas à informação ou às crenças individuais, mas a uma intrincada rede de incorporação que, de certa forma, se dá num processo de naturalização dos valores socialmente produzidos e que podem ser estruturados a partir da apropriação do discurso científico.

No acervo das nossas fontes, o "tomar banho" como prevenção do HIV/AIDS beira a um verdadeiro mito:

Porque tem a mina que tem relação com um [homem] sem camisinha, aí não toma um banho, aí vai assim com outro [homem] e [...] quando vai ver aí já era. O ultimo que foi, ficou pegado. Já era, não tem o que fazer (Rufino)

Essa fala emblemática nos chama a atenção para a reprodução de noções do ideário higienista que consagra a limpeza como solução dos problemas de saúde. Nesse sentido, a limpeza muito difundida como medida sanitária relacionada à prevenção de várias doenças, quando é considerada como prevenção do HIV/AIDS, pode se tornar um mito.

Há ainda casos em que opiniões tanto revelam preconceitos como mitos. Isso se faz muito presente ao se considerar que as relações com pessoas desconhecidas requerem a adoção de medida preventiva, via uso do preservativo, enquanto que as conhecidas justificam a não adoção dessa prevenção. Os trechos das falas que seguem ilustram esse hibridismo.

Mas, se for uma pessoa de fora e desconhecida eu já penso diferente [uso preservativo] (Rivo)

É uma mina que, porra, que eu tive bastante tempo pra conhecer ela, então tem um, esse, a confiança nela, entendeu, e ela tem em mim também (Reinaldo)

Ele [amigo] fala abertamente 'cara, eu transo sem camisinha porque eu confio na minha mulher, eu faço relação, eu tenho relação sexual com ela faz mais de cinco anos, vai fazer seis anos, porque eu transaria com camisinha com ela? (Randal)

Nessas falas, de um lado, observa-se certo mito de que a pessoa desconhecida é a priori suspeita de transmitir a doença e, de outro, destacase que o preconceito de certa forma recai na mulher, considerada a fonte da transmissão.

Indo na direção desse preconceito, que atravessa as relações de gênero, alguns jovens apontam a permanência de referenciais calcados em um tipo ideal do feminino identificada com uma mulher recatada, passiva e com quem se pode abrir mão do preservativo, em relação a um outro perfil de mulher que tem uma atitude ativa identificada como "fácil" e com quem se deve a principio utilizar camisinha. 
Esse achado se associa às conclusões de Guerreiro et al. ${ }^{6}$ e Madureira e Trentini ${ }^{30}$ que destacam as categorias "inocente" e "perigosa", em uma oposição binária que retrata o sentido atribuído às mulheres que possivelmente podem e as que não podem contaminar os homens. Ou seja, homens que fazem uso de preservativo, quando encontram uma mulher que corresponde à ideia de "inocente" são instados a abandona-lo, uma vez que tal mulher deixa de pertencer aos "outros" e passa a ser "conhecida”. Caminhando nessa mesma lógica, o estudo de Taquete ${ }^{31}$ destaca que com as jovens classificadas como "difíceis" se dá o namoro e a partir daí permite-se o abandono do preservativo. As "difíceis", por sua vez, convergem com a "conhecida", pois conhecer nesse ângulo é antes saber supostamente da vida sexual da parceira e se ela tende aos pré-requisitos de poucos parceiros, passividade e recato.

Ainda que as mulheres desconhecidas e as que não são consideradas confiáveis sejam recorrentemente vistas como parcerias que demandam uma prevenção por meio do uso do preservativo, insurge no interior das falas dos nossos sujeitos uma crítica a esse posicionamento:

O certo seria [sempre se prevenir] porque [...], hoje em dia, até com a mulher [com quem se] casa [...] os médicos falam [que] é pra se prevenir [...], mas, até então, eu acho que a maioria [...] não faz essa prevenção (Reinaldo).

Por outro lado, parece surgir um novo mito relacionado ao exame sorológico/HIV visto como um possível método de prevenção, já que a partir do conhecimento da sorologia dos parceiros, estes poderiam abandonar o uso do preservativo.

[...] ter essa consciência de já que vai se relacionar seriamente com a mulher eles ta fazendo, pedindo pra mulher e a mulher ta pedindo pro homem certo, pra ta fazendo um exame pra, ai sim poder ta, podendo fazer um sexo, não seguro totalmente mais, em ambas as partes, mais seguro... (Reinaldo).

Talvez uma hipótese explicativa para a valorização do teste como medida preventiva se relacione ao fato dessa geração estudada (homens jovens) pouco ter retido na memória o impacto que a epidemia da AIDS causou nas relações afetivo-sexuais, o que de certa forma acarretou um agir de práticas muito distanciadas das primeiras orientações da política de saúde de combate ao HIV. O avanço da medicina fez com que a AIDS deixasse de figurar como uma doença letal e se tornasse crônica ${ }^{32}$.

Nesse sentido, com o deslocamento da concepção da doença como algo terminal que muda para a qualificação de cronicidade, faz com que o comportamento da geração mais jovem não considere que a infecção seja algo necessária a ser evitada e combatida. Ainda no imaginário desses jovens encontra-se muito mais presente o uso do preservativo como algo temporário para o estabelecimento de uma relação de confiança do que de fato um método que gere um comportamento de práticas de sexo mais seguras ${ }^{17}$.

É importante perceber que essa fala suscita as noções do teste como aquele que pode garantir segurança ao estabelecer a condição sorológica dos parceiros, por outro lado, pode ser considerado um avanço o fato de o exame ter sido visto dentro do escopo relacionado à prevenção.

Pois, apesar de se considerar que os segmentos populacionais mais vulneráveis tenham dificuldade de ter acesso ao exame sorológico de $\mathrm{HIV}^{33}$, há estudo ${ }^{34}$ que aponta outra direção, uma vez que tal exame é gratuito, podendo ser assegurado às pessoas, independente da sua posição socioeconômica. Entretanto, nem sempre tal procedimento está disponibilizado nos serviços, acrescido ao fato de que há uma invisibilidade dos homens como protagonistas dos serviços, levando uma ausência de discussão entre profissionais de saúde e usuários acerca da contribuição do exame para as práticas de prevenção.

Nesse sentido, a discussão que tem sido feita em relação ao Sistema Único de Saúde (SUS) é que apesar de seus avanços, muito ainda há que ser feito para a efetiva implementação do sistema, no entanto é fato que um de seus princípios, a universalização tem sido um diferenciador, consagrando dentre outros um marcador de inclusão na saúde.

Todavia, a universalização pode ser uma questão, uma vez que o segmento masculino nem sempre acessa os serviços de saúde, fator considerado fundamental no aspecto programático da vulnerabilidade ${ }^{2}$. Esse dado pode ser confirmado em pesquisa realizada por Gomes e Nascimento ${ }^{4}$ em 2006. Tal pesquisa revelou que os homens procuram menos os serviços de saúde do que as mulheres e que o grau de instrução influencia na adoção de medidas preventivas.

No que tange ainda à política do Sistema Único de Saúde, ele tem se organizado para contemplar um conjunto de situações que estão preconizados nas diretrizes da política, assim o teste sorológico foi amplamente difundido e universalizado nas unidades de saúde, houve intensa campanha e qualificação desses profissionais para a incorporação da solicitação do exame como uma rotina do processo de trabalho, investimen- 
tos considerados mais humanizados para o anúncio do resultado compuseram uma nova forma de olhar para a epidemia de AIDS. O exame passou então a ter um status de prevenção primária e não secundária como de fato o é. Outro fator em relação à visibilidade do exame tem a ver com a popularização dos serviços de saúde nas unidades básicas, na qualificação da mão de obra especializada e no sistema de acolhimento à população que vive com HIV ${ }^{34}$.

Do mesmo modo, quando o teste passa a ser incorporado como rito de passagem para a liberação do uso do preservativo, pode sinalizar o seu entendimento como instrumento que formaliza uma nova fase da relação onde o outro não pode ser mais visto com desconfiança e receio, ao passo que se institui em um novo momento de entrega em que a camisinha parecerá então uma barreira ao próprio amor ${ }^{35}$.

Assim, podemos dizer que a percepção dos sujeitos sobre a realização do teste pode tornálos vulneráveis, uma vez que o percebam como um contrato onde os envolvidos deixam de experimentar outras relações afetivo-sexuais, o que difere do objetivo do teste, que é o de constatar a existência ou não do vírus e, ao mesmo tempo, ao estabelecer esse pacto não são consideras informações importantes, como por exemplo, a existência do período de janela imunológica.

\section{Considerações Finais}

Nossa discussão aponta que a adesão ao modelo de masculinidade hegemônica - que tem como marcas identitarias a heterossexualidade compulsória, as relações hierárquicas e opressoras de gênero - compõem um quadro onde os homens heterossexuais historicamente concebidos como não vulneráveis ao HIV tornam-se suscetíveis à contaminação a partir da incorporação desse modelo.

Essa vulnerabilidade é moldada a partir das relações e das formas de operação do sistema sexo/ gênero em nossa sociedade. Este acaba por ser responsável em fixar referenciais de masculino e de feminino, ditando tom sobre a conduta sexual de homens e mulheres em nossa sociedade.

Assim, é possível refletir que essa lógica tende a conceber sexualidade e gênero a partir de marcadores que reproduzem formas conservadoras e hierárquicas, constituindo-se em um dos pilares da vulnerabilidade masculina.

Nossos dados associados à discussão de outros estudos apontam para a existência de uma dada porosidade do modelo hegemônico de gênero, possibilitando, portanto, investimentos outros que possam promover ações no sentido de acolher subjetividades outras que tenham tido até agora pouca visibilidade.

A perspectiva do estabelecimento do preservativo como desnaturalizador das relações afetivo sexuais, como impeditivo da entrega total ao outro, age como dado importante no abandono da camisinha ${ }^{36}$. A maneira como se organiza o sistema sexo/gênero pode distanciar do masculino a ideia do cuidado e da utilização do preservativo como uma forma de afeto e de cuidado com o "outro".

Ainda nessa direção, a vulnerabilidade dos homens jovens se dá em diversas áreas e não apenas na não adoção permanente do uso do preservativo, e essa resistência precisa superar o discurso que valoriza apenas o acesso à informação como forma de prevenção. Outros aspectos devem ser considerados: a forma como essa informação chega aos sujeitos, em que linguagem e se suas expectativas são consideradas.

Indo nessa direção, um dos instrumentos que podem se articular ao fortalecimento das políticas públicas para esse segmento é a adoção de uma escuta efetiva dos homens jovens, pois pode estimular adesão às informações sobre a saúde e envolver os sujeitos nas ações de prevenção e promoção da saúde.

Por outro lado, a reprodução de discursos acerca de práticas sexuais de maior e menor "risco", pode fomentar uma noção que coloca algumas práticas como "perigosas" e outras como "inocentes", baseadas na forma como alguns desejos são posicionados dentro do que é considerado como "normalidade" e "anormalidade", não por acaso recai sobre o sexo anal o perigo e o sexo vaginal estaria no polo oposto. O que contribui diretamente na vulnerabilidade dos homens heterossexuais, já que a sua prática sexual está dentro do socialmente correto ${ }^{37}$.

É possível pensar que para caminharmos na discussão de prevenção precisamos colocar na ordem do dia a construção do sistema sexo/gênero, em volta do qual se articulam os significados sociais da masculinidade e da feminilidade que influenciam estruturalmente o plano das relações afetivo sexuais, em geral, e na prevenção do HIV/AIDS, em específico.

Consoante a isso se faz necessário rediscutir os mitos e os preconceitos que ainda envolvem a contração do vírus HIV. Neste sentido, as estratégias de prevenção precisam contribuir para uma reflexão acerca de como são experienciadas dia- 
riamente as informações acerca do HIV/AIDS. Acreditamos que isso só é possível a partir da superação da lógica mecânica da mensagem acerca do uso do preservativo e que se incorpore a discussão acerca das dimensões que atravessam a decisão acerca desse uso.

\section{Colaboradores}

JSM Junior, R Gomes e EF Nascimento participaram igualmente de todas as etapas da elaboração do artigo.

\section{Referências}

1. Alves MFP. Sexualidade e prevenção de DST/AIDS: representações sociais de homens rurais de um município da zona da mata pernambucana, Brasil. Cad Saude Publica 2003; 19(Supl.2):S429-S439.

2. Ayres JR C, Freitas AC, Santos MAS, Saletti Filho HC, França JR I. Adolescência e AIDS: avaliação de uma experiência de educação preventiva entre pares. Interface Comun Saude Educ 2003; 7(12):113-128.

3. Gomes R. Sexualidade masculina, gênero e saúde. Rio de Janeiro: Editora Fiocruz; 2008.

4. Gomes R, Nascimento EF. A produção do conhecimento da saúde pública sobre a relação homemsaúde: uma revisão bibliográfica. Cad Saude Publica 2006; 22(5):901-911.

5. Silva WA, Buchalla CB, Paiva V, Latorre MRDO, Ron Stall R, Hearst N. Prevenção de doenças sexualmente transmissíveis e AIDS entre jogadores juniores. Rev Saude Publica 2002; 36(Supl. 4):68-75.

6. Guerriero I, Ayres JRCM , Hearst M. Masculinidade e vulnerabilidade ao HIV de homens heterossexuais, São Paulo, SP. Rev Saude Publica 2002; 36 (Supl.4):50-60.

7. Vilela WV, Doreto DT. Sobre a experiência sexual dos jovens. Cad Saude Publica 2006; 22(11):24672472.

8. Villarinho L, Bezerra I, Lacerda R, Latorre M RDO, Paiva V, Stall R, Hearst N. Caminhoneiros de rota curta e sua vulnerabilidade ao HIV. Rev Saude Publica 2002; 36(4):61-67.

9. Rios LF, Parcerias e práticas sexuais de jovens homossexuais no Rio de Janeiro. Cad Saude Publica 2003; 19(Supl.2):S223-S232.

10. Antunes MC, Peres CA, Paiva V, Stall R, Hearst N. Diferenças na prevenção da AIDS entre homens e mulheres jovens de escolas públicas. Rev Saude Publica 2002; 36(Supl.4):88-95.

11. Buchalla CM, Paiva V. Da compreensão da vulnerabilidade social ao enfoque multidisciplinar. Rev Saude Publica 2002; 36(Supl. 4):117-119.

12. Connell RW. On hegemonic masculinity and violence: response to Jefferson and Hall. Theoretical Criminology 2002; 6(1):89-99.

13. Welzer-Lang DA construção do masculino: dominação das mulheres e homofobia. Rev Estud Fem 2001; 2(9):460-482.

14. Greig A. Sexo e os direitos do homem. In: Cornowe11 A, Jolly S, organizadores. Questões de sexualidade: ensaios transculturais. Rio de Janeiro: Associação Brasileira Interdisciplinar de AIDS (ABIA); 2008. p. 167-174. 
15. Czeresnia D. Ações de promoção à saúde e prevenção de doenças: o papel da ANS. Brasília: Agência Nacional de Saúde (ANS); 2003.

16. Bastos FI, Szwarcwald CL. AIDS e pauperização: principais conceitos e evidencias empíricas. Cad Saude Publica 2000; 16(Supl.1):65-76.

17. Paiva VL, Pupo R, Barboza R. O direito à prevenção e os desafios da redução da vulnerabilidade ao HIV no Brasil. Rev Saude Publica 2006; 40(Supl.):109-119.

18. Feliciano KVO. Prevenção da AIDS entre os jovens: significados das práticas e os desafios à técnica. Rev. Bras. Saúde Mater. Infant 2005; 5(4):429- 438.

19. Munoz Sanchez A, Bertolozzi MR. Pode o conceito de vulnerabilidade apoiar a construção do conhecimento em Saúde Coletiva? Cien Saud Colet 2007; 12(2):319-324.

20. Mann J, Tarantola DJM, Netter TW, organizadores. A Aids no mundo. Rio de Janeiro: RelumeDumará; 1993.

21. Parker R, Camargo Jr KRC. Pobreza e HIV/AIDS: aspectos antropológicos e sociológicos. Cad Saude Publica 2000; 16(Supl.1):89-102.

22. Gomes R. Sentidos atribuídos à sexualidade masculina e aos cuidados de saúde [projeto de pesquisa]. Rio de Janeiro: Instituto Fernandes Figueira (IFF), Fundação Oswaldo Cruz (Fiocruz); 2006.

23. Minayo MCS. O desafio do conhecimento: pesquisa qualitativa em saúde. São Paulo: Editora Hucitec; 2006.

24. Gomes R. Análise e interpretação de dados de pesquisa qualitativa. In: Minayo MCS, organizador. Pesquisa social: teoria, método e criatividade. Petrópolis: Editora Vozes; 2007. p.79-108.

25. Vaitsman J. Flexíveis e plurais. Identidade, casamento e família em circunstâncias pós-modernas. Rio de Janeiro: Editora Rocco; 1994.

26. Maiolino ALG, Silva AM, Souza DC, Cabral LH, Victor TAS. O uso do solo urbano: históricas desigualdades, novas leis e algumas percepções de moradores da favela da rocinha. Estud Pesq Psicol 2007; 7(2):243-256.

27. Pereira DF, Lima DA. O Adolescentro Paulo Freire e suas estratégias para a promoção e prevenção de saúde valorizando o protagonismo juvenil. In: $R e-$ sumos ampliados do VI Seminário do Projeto Integralidade, 2006. [Documento da internet].[acessado 2011 jan 10]. Disponível em: http://www.lappis.org.br/download/Resumos_VIS_lercap2.pdf
28. Francelin MM. Ciência, senso comum e revoluções científicas: ressonâncias e paradoxos. Ci. Inf. Brasilia 2004; 33(3):26-34.

29. Pelúcio L. As Maravilhas do sexo que ri de si mesmo. Cad. Pagu 2007; 29:481-489.

30. Madureira VSF, Trentini M. Da utilização do preservativo masculino à prevenção de DST/AIDS. Cien Saude Colet 2008; 13(6):1807-1816.

31. Taquete SR, organizadora. Aids e juventude: gênero, classe e raça. Rio de Janeiro: Eduerj; 2009.

32. Asineli-Luz A, Fernandes Junior N. Gênero, adolescências e prevenção ao HIV/aids. Pro-Posicões 2008; 19(2)56:81-97.

33. França Junior I, Calazans G, Zucci E M. Mudanças no âmbito da testagem anti-HIV entre 1998 e 2005. Rev Saude Publica 2008; 42(Supl. 1):84-97.

34. Araújo CLF. Os Centros de Testagem e Aconselhamento (CTA) no município do Rio de Janeiro e o acesso ao diagnóstico do HIV entre e População Negra: uma análise qualitativa. Saúde Soc 2010; 19(Supl. 2):85-95.

35. Jeolás LS. Os jovens e o imaginário da Aids: entre o risco e a prevenção Sev. Soc.Rev 1999; 2(1):11-53.

36. Heilborn ML. Entre as tramas da sexualidade brasileira. Rev Estud Fem 2006; 14(1):43-59.

37. Pelúcio L, Miskolci R. A prevenção do desvio: o dispositivo da aids e a repatologização das sexualidades dissidentes. Sexualidadade, Saúde e Sociedade Revista Latino Americana [periódico na Internet]. 2009 [acessado 2011 jan 05];(1):125-157. Disponível em: http://www.sexualidadsaludysociedad.org

Artigo apresentado em 16/03/2011

Aprovado em 01/04/2011

Versão final apresentada em 09/06/2011 